\title{
Ethnoforgery AND OUtSider Afrofuturism
}

\author{
• \\ TRACE REDDELL \\ UNIVERSITY OF DENVER (US)
}

\begin{abstract}
This essay detours from Afrofuturism proper into ethnological forgery and Outsider practices, foregrounding the issues of authenticity, authorship and identity which measure Afrofuturism's ongoing relevance to technocultural conditions and the globally-scaled speculative imagination. The ethnological forgeries of the German rock group Can, the work of David Byrne and Brian Eno, and trumpeter Jon Hassell's Fourth World volumes posit an "hybridity-at-the-origin" of Afrofuturism that deconstructs racial myths of identity and appropriation/exploitation. The self-reflective and critical nature of these projects foregrounds issues of origination through production strategies that combine ethnic instrumentation and techniques, voices sampled from radio and TV broadcast, and genre-mashing hybrids of rock and funk along with unconventional styles like ambient drone, minimalism, noise, free jazz, field recordings, and musique concrète. With original recordings and major statements of Afrofuturist theory in mind, I orchestrate a deliberately ill-fitting mixture of Slavoj Žižek's critique of multiculturalism, Félix Guattari's concept of "polyphonic subjectivity," and Marcus Boon's idea of shamanic "ethnopsychedelic montage" in order to argue for an Outsider Afrofuturism that works along the lines of an alternative modernity at the seam of subject identity and technocultural hybridization. In tune with the Fatherless sensibilities that first united black youth in Detroit (funk, techno) and the Bronx (hip-hop) with Germany's post-WWII generation (Can's krautrock, Kraftwerk's electro), Outsider Afrofuturism opens up alternative routes toward understanding subjectivity and culture-through speculative sonic practices in particular-while maintaining social behaviors that reject multiculturalism's artificial paternal origins, boundaries and lineages.
\end{abstract}

KEYWORDS: Afrofuturism; ethnoforgery; outsider music; appropriation; technoculture; multiculturalism; speculative imagination

Dancecult: Journal of Electronic Dance Music Culture 5(2): 88-112 ISSN 1947-5403 @2013 Dancecult http://dj.dancecult.net DOI 10.12801/1947-5403.2013.05.02.05

dsncecult 
TRACE ReDdell is a writer, theorist and artist exploring the interactions of sound and the cosmological imagination. His publications include articles in Leonardo Music Journal, the Contemporary Music Review, the Electronic Book Review, Cybersounds: Essays on Virtual Music Culture (Peter Lang Publishing, 2006), "Cyborg Ritual and Sentic Technology in the Vortex Concerts" in The Poetics of Space: Spatial Explorations in Art, Science, Music \& Technology (Sonic Acts Press, Paradiso, 2010). His first book, Sonic Science Fiction, is forthcoming from the University of Minnesota Press. Trace is an Associate Professor at the University of Denver, where he teaches in the Emergent Digital Practices program.

Unhappy is he to whom the memories of childhood bring only fear and sadness. ... Such a lot the gods gave to me-to me, the dazed, the disappointed; the barren, the broken. And yet I am strangely content and cling desperately to those sere memories, when my mind momentarily threatens to reach beyond to the other.

-H. P. Lovecraft, “The Outsider”, Weird Tales, April 1926

I'd say that anything I'm doing is simply my misunderstanding of black music.

-Brian Eno, Sounds, 7th March 1981

THE STORY OF ETHNOFORGERY in popular music is full of imitations, re-creations, studies and rip-offs that trace the troubled history of so-called race relations in popular music. Elvis Presley, Robert Plant, George Harrison, Eminem and Michael Jackson are some of the more high-profile cases that have all been charged with ethnological forgery of one sort or another. These popular identities exist on the threshold of sonic expression and racial coding, and they are often described as violators of race-based assumptions about what the proper place is, and who the proper person, for which proper and appropriate sonic behaviors. Ethnological forgery suggests an extreme end of the scale by which we might measure how different cultures borrow the stuff of sounds and music from each other. This "stuff" could include anything from unique vocal styles, dialects, accents or other languages altogether, to particular instruments, compositional practices, performance styles, or studio production and sound engineering techniques. What makes the forgery a forgery is the degree to which the fake claims its authenticity and whether it attempts to pass as a legitimate documentation or representation of another culture; the forgery fails to earn that distinction of authenticity because of a fundamental dispute over authorship.

I begin with questions of authenticity, authorship and race to get at some of the problems surrounding the kind of racial identification of music and sound cultures that tend to shape conceptualizations of Afrofuturism. A typical playlist would consist of selections from first generation musicians like Sun Ra, Parliament and Funkadelic, Lee "Scratch" Perry and Scientist; second generation cuts from Tricky, Cybotron, Larry Heard, A Guy Called Gerald, 
Afrika Bambaataa, Jeff Mills and Juan Atkins; and more contemporary tracks from dBridge, the Spaceape, Hydroponic Sound System, SBTRKT, Heavyweight Dub Champion, and Janelle Monae. This consigns Afrofuturism to history, treating it as evidence of a specific cultural moment, a phase that black musicians went through and continue to go through with varying levels of awareness of their own lineage.

But what if we add to our playlist a few misfits typically absent from the Afrofuturist discography? These could include the "ethnological forgeries" of the German experimental rock group Can; the independent work of David Byrne and Brian Eno, and their work with the Talking Heads; trumpeter Jon Hassell's Fourth World volumes; the first wave of UK dub by Adrian Sherwood (Creation Rebel, Dub Syndicate) and Richard H. Kirk's deeply dub-inflected Sandoz albums; and ambient dub and dubstep cuts from Noiseshaper, Beat Pharmacy, Kode9 and Burial. Should these artists also be classified as Afrofuturist (a category that has mostly come down to the cataloging of black musicians) simply by their adoption of Afrofuturist themes and sonic signifiers? This may make the more salient features of Afrofuturism so ubiquitous that it becomes a pointless signifier, subsequently losing its effectiveness as both a meme (a mutating genetic-like structure for transfer of ideas, styles, slang, etc.) and a trope (a pose that can be mobilized, affected, turned on, dropped, and so on).

This playlist expansion prompts us to consider whether Afrofuturism can include works and artists influenced by Africa though not of African descent, and if so, are these artists properly Afrofuturist or part of what we might call an Outsider Afrofuturism? And could the existence of such Outsider practices shape our understanding of Afrofuturism in new ways, particularly regarding the roles that Africa might play in a globally-scaled speculative imagination? At stake are the ways in which their inclusion problematizes the Afrofuturist playlist altogether. I will concentrate on the examples of Jon Hassell, Can, and Byrne and Eno. ${ }^{1}$ These Outsider Afrofuturist projects do some similar things. They incorporate new and interesting sounds from Islamic North Africa, Asia, Zimbabwe, South Africa, Jamaica, African-American hip-hop and elsewhere. These artists also share certain production and compositional strategies, combining ethnic instrumentation and techniques with sampled voices, environmental noises, and other recorded sounds. The compositions themselves tend toward rather unconventional, genre-mashing hybrids of styles like ambient drone, noise, free jazz, field recordings, minimalism and musique concrète. And when this music approaches popular forms like rock or funk, as it does frequently in all but Hassell's catalog, the musicians push popular sounds into dialogue with avant-garde forms and Outsider voices without progressive rock's move toward classical structures and romantic recuperation.

But it is not that Hassell, Can, or Byrne and Eno sound that much alike. Rather, what links them together is a shared self-awareness and critically reflective nature, which foregrounds issues of ethnology and authenticity, appropriation, identity, technology and culture-all themes that operate as meta-concepts in these works just as surely as they do in albums by Afrika Bambaataa and Janelle Monae. When detoured into ethnological forgeries (announced as such, rather than hidden) and Outsider practices, Afrofuturism 
is understood less as a matter of racial identification than a technocultural strategy that deconstructs racial myths of identity, appropriation and exploitation. I posit a kind of "hybridity at the point of origin", a deliberately ill mix of Slavoj Žižek's critique of multiculturalism, Félix Guattari's concept of "polyphonic subjectivity", and Marcus Boon's construction of shamanic "ethnopsychedelic montage" as a form of alternative modernity. The notion of the ill mix comes from Paul D. Miller (DJ Spooky aka That Subliminal Kid), who used the term "illbient" both to highlight the multicultural nature of Manhattan's digital arts scene in the early 1990s and describe a style of mixing reflected in Spooky's own work as well as that of DJ Olive, We, and the Subharmonic and Asphodel Record labels. Here, international, "world groove" beats and bass-heavy loops jump across styles and bpm's alike, combined within spacey soundscapes and snippets of spoken word that barely hold together a mix always already on the verge of falling to pieces. This strikes me as an appropriate way to describe the current critical project and its schizophonic tendencies to avoid clean conclusions and, in the words of David Byrne, to stop making sense.

This discussion attempts to mobilize a concept of poorly combined multiple identities residing in multiple worlds in order to jettison the universal singularity of the multiculturalist author. Despite his critique of multiculturalism's soft, liberal alterity, this is a move that Žižek would reject. Žižek embraces the Author/Other of the Father's Law as a way to mete out and measure both Subject identity and Social boundaries, founded on the casting (out) of Outsiders, and even as these hegemonies swap between minority and majority positions. Tempering Žižek's patriarchal subject, I have introduced ideas about multi-modalities of subjectivity and approach technocultural hybridization in ways more attuned to the Fatherless sensibilities and experiences that united black youth in Detroit (funk, techno) and the Bronx (hip-hop) with Germany's post-WWII generation (Can's krautrock, Kraftwerk's early electro). Fatherless cultures reject the Otherness that WWII generated along national and racial lines, and which Žižek's cultural theories reinstate. I follow Guattari and Boon's alternative routes toward understanding authorial subjectivity and culture-through sonic practices in particular-while maintaining social behaviors that reject multiculturalism's reinforced boundaries and lineages. This radically spatialized (rather than temporal) arrangement of hybrid subjectivities suggests that, more than a point in time, more than a genre even, Afrofuturism is a way of thinking and feeling one's way through the world. And like science fiction more generally, Afrofuturism reveals history to be contingent rather than teleological, always open to new interpretations, critical speculations and novel sensations. ${ }^{2}$

\section{INSIDE AFROFUTURISM}

The Definition of Afrofuturism that Mark Dery offers in "Black to the Future" doesn't hinge on the race of the author, but rather refers to the written work itself. Specifically, Afrofuturism indicates "speculative fiction that treats African-American themes and addresses African-American concerns in the context of $20^{\text {th }}$ century technoculture-and, 
more generally, African-American signification that appropriates images of technology and a prosthetically-enhanced future" (1994: 180). Dery's shift toward the cyborg strikes me as more specific than general but is in keeping with the broader inquiries into "cyberculture" collected in Flame Wars (1994). Nonetheless the language of this definition is open enough to apply to works by writers of any skin color, and it may be that we have no reason to postulate an Outsider Afrofuturism. We could even conclude that the national identity imposed by Dery's language need not apply, as long as speculation around African-American concerns and themes are articulated in the work. But this changes when Dery considers actual artistic process, where his emphasis on "African-American voices" narrows the practical application of the concept by racial and national indices considerably (182).

Dery's definition of Afrofuturism evolves from a simple but poignant question. Why are there so few African-American science fiction writers? He names four novelists in allOctavia Butler, Samuel R. Delany, Steve Barnes and Charles Saunders, as well as forerunner Ralph Ellison, for Invisible Man (1947) - and pretty much exhausts the pool. This is indeed a perplexing absence because science fiction, Dery remarks, is "a genre whose close encounters with the Other-the stranger in a strange land-would seem uniquely suited to the concerns of African-American novelists" (1994: 179-80). Perhaps, though, this is exactly the reason why it doesn't work for many African-Americans. The resonance is set too high, and we experience something like the masking encountered in sound mixing when two opposing frequencies cancel each other out. Dery thinks that the African-American writer should naturally gravitate toward science fiction because "the sublegitimate status of science fiction as a pulp genre in Western literature mirrors the subaltern position to which blacks have been relegated throughout American history" (180). He sets up this dynamic using a few different metaphors, though his initial formulation of Afrofuturism in terms of parallel ghettos is unappealing. ${ }^{3}$ But in an interview with Dery, African-American cultural critic Greg Tate suggests something more like my idea of masking and cancellation when he claims that science fiction fails to appeal to African-Americans because they "live the estrangement that science-fiction writers imagine" (cited in Dery 1995: 208). ${ }^{4}$ Tate presents us with the question of access to technology as well as to the future-two terms frequently conflated in science fiction. Because a sense of access to the future is at the core of the speculative imaginary, it may be that blockage at these two points of access has prohibited many African-Americans from finding science fiction a compelling textual or literary form. At the same time, it is an awareness of this blockage that will account for the general turn of the Afrofuturist imagination toward music and sound production.

While shifting specifically to racial concerns, both Dery and Tate echo earlier proclamations by J. G. Ballard regarding the ubiquitous science fiction landscape of the latter $20^{\text {th }}$ century. In this "future of the past" that we inhabit, Ballard suggests, reality is dystopic and violent, disaffecting and pornographic. It is also deeply unreal. "We live inside an enormous novel", Ballard writes in the introduction to the 1974 French edition of Crash. "For the writer in particular it is less and less necessary for him to invent the fictional content of his novel. The fiction is already there. The writer's task is to invent the reality" 
(1974: 5). This sentiment plays out as Afrofuturist artists turn not toward fiction and its representations of the future, much less representations of blackness in the future, but rather toward the actual sound technologies of musical production. This turn embodies the kind of technological access that Tate describes. Afrofuturism evades or displaces questions of representation in favor of creating the future itself. In Dery's article, we experience this evasion and displacement through a shift into other forms of "signification" and "images" than writing, and Dery's catalog of major Afrofuturists grows to include film makers, painters, graffiti artists, theorists, and comic book creators. ${ }^{5}$ But it is in music of some form or another that we find Dery's most extensive survey of Afrofuturist practitioners. ${ }^{6}$ Dery knew very well that he was riding on a shared wave of mounting Afrofuturist rhythms, and that his essay was meant to be neither comprehensive nor exclusive. ${ }^{7}$ Kodwo Eshun's More Brilliant Than the Sun (1998) significantly extends the Afrofuturist canon by pushing past the almost exclusively American borders of Dery's original construction. But the conceptual push that Eshun achieves is even more significant. A critical hybrid of Deleuzian post-structuralist philosophy, weird science, music history, and the atmosphere and attitudes of the UK jungle music scene, Eshun's theoretical work reveals the strategic, toolkit-like nature of Afrofuturism as a critical practice. That is, Eshun shows Afrofuturism to be a way of thinking capable of transferring strategies across radically different modes of media production (say, from jungle vinyl distribution to academic publishing). Not a genre then, but a set of conceptual tools and models to put into motion, Afrofuturism comes to signify how music provides ways to "technologize" the self along with the future, and to participate in the "future-fication" of culture, as it were. Afrofuturism by-passes established strategies of representation in favor of embodiment as the Outsiders, Aliens, and Cyborgs of science fiction. Detroit techno producer Juan Atkins lives up to the technologizing part by proliferating his work through a number of pseudonyms such as M500, X-Ray, Channel One Frequency, Audiotech and Cybtotron, an electro outfit with the similarly technified 3070 (Richard Davis) and Jon-5 (John Housely). ${ }^{8}$

The multiple 12-inch Cybotron cuts released throughout the 1980s and finally collected on the Clear LP (1990) gather several threads of influential media from the early 1980s that celebrated, commented on and enabled this arrival of the future into the present of digitized technoculture: Tron, Blade Runner, Mad Max, video games and the personal computer world of Kraftwerk. Cybotron dedicate Clear "to the people of the Detroit Metroplex" with a word of advice: "To survive we must technofy and save the biosphere" (cited in Eshun 07[103]). Atkin's variously technologized pseudonyms and multiple project identities resonate with the notion of "the production of polyphonic subjectivity" that Guattari discusses in Chaosmosis (1995). Not only does Atkins recognize that subjectivity is produced, but multiple subjectivities can be assembled and arrayed in a single instantwhat Guattari calls "resingularisation" throughout his work. This concept lets us get at the nature of identity formation in the Afrofuturist practice of Juan Atkins. Guattari plugs identity formation directly into the technocultural mix through the highly conceptual language of machinery and the arts, and he frequently measures partial subjectivities in 
terms of musical properties: "harmonies, polyphonies, counterpoints, rhythms, and existential orchestrations, until now unheard and unknown" (1995: 18-9). Guattari's shared emphasis on the machinic and the musical is wholly sympathetic to the Detroit techno scene and Afrofuturism more generally, suggesting what Eshun finally splices into the hybrid neologism, "futurhythmachine". Associating identity with rhythm in technocultural assemblages is particularly useful as we seek to understand how subjectivity forms in highly saturated media environments.

Atkin's multiple machinicidentities-each associated with a distinct, often microscopically distinguished, rhythmic sub-genre or piece of gear-play out the heterogeneity of subjectivity in terms of rhythmic productivity, exploiting what Guattari calls the "machinic dimensions of subjectivation" (1995: 4). Atkins' machinic identifiers set aside race markers for technological signifiers. That subjectivity should emerge and resingularise as a machinic array-which is automatable and repeatable through the sequence and loop of electronic production-is what leads Guattari, Eshun and Atkins alike to rhythmic song as a way of understanding multiversal territory within the collective sonic ecology of a mediascape. The hypermedia landscape to which Guattari alludes situates "partial fragments of enunciation operating as 'shifters' of subjectivation. ... What does matter is the mutant rhythmic impetus of a temporalisation able to hold together the heterogeneous components of a new existential edifice" (1995: 20). Rhythm holds the media fragments together while also providing vehicles for transfer and exchange, making these media fragments the source of potential, polyphonic subjectivities that emerge, in the case of Cybotron (and the Bronx's Afrika Bambaataa, as well), from an unlikely mixture of German electronic groups (Kraftwerk and Tangerine Dream), Spaghetti Western and sci-fi soundtracks, Gary Numan, European and American Industrial music, metal and hip-hop.

Atkins mobilizes "himself" into multiple identities for the same reason that Guattari comes back to song again and again-multipartite, multilayered song forms in particular. Guattari valorizes song as the expressive form of "partial subjectivity", which is "prepersonal, polyphonic, collective and machinic" (1995: 21). The Cybotron album plays this out as a cyberpunk narrative of identity formation in which subjectivity is measured in terms of the alterities contained within it and that bound it in the form of existential Territories to be borrowed from. Atkins' multiple subjective alterities might lead us to suspect that this Outsider exists at the heart of Afrofuturism, and we wouldn't be far off the point. But we might not yet understand what this means for traditional notions of race and nationality that privilege lines of influence, heredity and allegiance to Source over what Guattari calls the "ensemble of conditions which render possible the emergence of individual and/or collective instances as self-referential existential Territories, adjacent, or in a delimiting relation, to an alterity that is itself subjective" (9). I am interested in how the triad of "ensemble", "emergence" and the "existential" contribute to future-oriented models of subjectivity.

In order to address head-on the relationship between black music and white music, Eshun's discussion of Cybotron stages "futurity" as an overflow of the production of 
polyphonic subjectivities. Of course, the future has to come from somewhere. Juan Atkins, who first becomes cyborgized with the label version of Model 500, describes hearing the mannikin-white, German electronic band Kraftwerk the first time: "It was the answer. It was the future for me" (cited in Eshun 1999: 07[105]). "Futurity" frustrates the accounts of sequential lineages - that is, of parentage and heritage - that typically inform and frame discussions of influence among and across black and white musicians. Without citing anyone in particular, Eshun describes the perplexed response by white journalists to the fact that an archetypically white group like Kraftwerk had influenced musicians like Grandmaster Flash, Afrika Bambaataa and Juan Atkins. How could these black guys even like such an archetypically white group as Kraftwerk? Eshun's response shifts the question of influence to one of "attractions:" "Bambaataa is attracted to an alien Euro sound, bored with and indifferent to familiar [African-American] sound. But at the same time, white sound isn't alien at all. Nothing that attracts is alien. Bambaataa wants to artificialize himself. ... The Futurist moves carelessly past a polarization which was never there" (07[105]). The problem with the question is that there should even be a question of the influence of "this whitest of groups" over "Black Music". It is a flawed question, and it epitomizes the post-colonial perspective targeted by Slavoj Žižek's critique of multiculturalism-to which we now turn.

\section{An OUtSider Afrofuturism}

As narratives of Africa and the Afrodiaspora infuse the technological and speculative imagination, we have an opportunity to reflect on the notion of The Outsider as an ethical and philosophical figure. I adopt this term as distinct from "the Other" partly in order to position a category for framing racial and national phenomena in ways different than that of multiculturalism. Why is this move necessary? As Žižek argues in "Multiculturalism, or the Cultural Logic of Multinational Capitalism" (1997), the respect for the identity of the Other that is at the heart of multiculturalism is itself "a disavowed, inverted, self-referential form of racism" disguised as respect and sustained by distance. Perceiving the Other as a member of "a self-enclosed 'authentic' community", the multiculturalist maintains distance from the Other, occupying instead "the privileged empty point of universality" (Žižek, 1997: 44). Multiculturalism provides "the ideal form of ideology" for post-colonial capitalism because it too acts "from a kind of empty global position" and "treats each local culture the way the colonizer treats colonized people - as 'natives' whose mores are to be carefully studied and 'respected"' (44). As global capitalist self-colonization follows from traditional imperialist colonialism, multiculturalism follows from Western cultural imperialism-a postcolonial culturalism that "involves patronizing Eurocentrist distance and/or respect for local cultures without roots in one's own particular culture" (44). By this argument, distance maintains control, though Žižek's language does not entirely account for the role that media fragments serve, as attractors and shifters, to circumvent the distance meant to prevent cross-cultural exchange and contamination. Let's see how these ideas might provide a way to measure some recent Afrofuturist criticism. 
In Fear of Music: Why People Get Rothko but Don't Get Stockhausen (2009), David Stubbs treats Afrofuturism as the ubiquitous and primary thread of all "black music" since jazz, which "from Armstrong to Coleman, Hendrix to George Clinton, from hiphop through to dubstep, has always been futuristic, and as such a reflection of black experience. On the one hand, black music is constantly obliged to stay one step ahead of its white imitators (and in so doing, provides a perpetual supply for said imitators). However, it's also because the black dream is largely one of tomorrow, not yesterday or even today, which aren't generally times on which black people would particularly want to dwell" (57-8). Rejection of both a painful past and present realities is posited as the key to embracing the future, which holds for black musicians "the possibility, at least, of improved circumstances" (116). The futurism that Stubbs posits at the heart of "black music" comes of the fact that this music "has never been overly weighed down by any great wistful retrospection" (116).

Stubbs's assessment is simultaneously compelling and deeply problematic, even stifling in its over-generalization of the one-way relationship between "black" and "white" music. For Stubbs, "black music" invariably takes the lead, is always primary to the secondary of "white music", especially in terms of popular formats. "Black music" innovates, Stubbs tells us, while "white music" imitates. At the same time, Stubbs situates the black musician at a strangely vacated or even evacuated point of culture and history, adrift without a past, and lost without a present. This notion is so awfully out of touch with much of the greatest "black music" ever recorded as to be absurd. ${ }^{9}$ Further, even if "yesterday" as history may be avoided, "yesterday" as myth emerges consistently throughout Afrofuturism since the 1950s in the works of artists as diverse as Sun Ra, George Clinton and Drexciya. Sun Ra combines Egyptian mythology with UFOlogy to create an alternative to the race and nation-based politics of the American black power movement and inner-city youth and values instead mythic, divine and cosmic perspectives. George Clinton's P-Funk projects brew up his own pantheon of recurring, mythically cast characters like the Star Child, Sir Nose Devoid of Funk, and the Brides of Dr. Funkenstein. Drexciya's, well, Drexciyans, are a race of afronauts evolved from the unborn children of pregnant Africans thrown from slave ships; they resemble something inbetween Aquaman's African-American nemesis, Black Manta, H.P. Lovecraft's Deep Ones, and the Creature from the Black Lagoon. In each case, these pop myths emphasize the role of the advanced sound technologies by which the Outsider-Sun Ra's Arkestra, Clinton's funkanauts, Drexciya's Drexciyans-transports listeners beyond familiar Earthly perspectives into neighboring alternate realities.

Near the conclusion of his book, Stubbs reasserts a basic distinction between an inherently futuristic "black music" and popular "white music", the latter of which, Stubbs argues, is caught up in the episodic recasting and recombination of its own histories when it is not stealing from black music. This recasts Žižek's take on multiculturalism through an onerous account of white music's "respect" for black music, which tends to distance the source behind a veil of respect and so enables theft to occur in the name of a more generally touted influence-say, that bit at Earl's Court in 1975, when Robert Plant attributes authorship of "In My Time Of Dying" to "the deep South of America" that has "made it's 
way into Earl's Court. If you can believe". ${ }^{10}$ Plant's spoken introduction to the sprawling jam that takes off from the traditional Gospel blues of "In My Time Of Dying" is meant as a kind of self-bestowing of the uncanny, an evocation of something so old, shaggy and black that it is nameless. It comes across, however, like a textbook example of the imitation and appropriation encountered throughout the history of rock music, exasperated further by the fact that on record, "In My Time Of Dying", is one of very few Zeppelin tracks credited to all four members of the band rather than to Blind Willie Johnson, to whom most ' $60 \mathrm{~s}$ artists, beginning with Bob Dylan, attributed the song. To complicate things, however, this account is also emblematic of the oversimplification enacted by purely racialized accounts of the history of music and how technology facilitates the transfer of music from one culture to another.

In many ways, Plant's attribution of the song's authorship to a fundamentally anonymous source is entirely appropriate. Blind Willie Johnson wasn't the first to compose but rather the first to record "In My Time Of Dying", a song widely covered throughout the South before migrating to Chicago and New York. And though Johnson's song is clearly "In My Time Of Dying", he recorded the cut as "Jesus Make Up My Dying Bed". How one reads these obscurities of authorship has much to do with one's sense of influence, repetition, imitation and forgery. These same uncertainties should complicate rather than strengthen the impulse behind racial and ethnological codings. As with Dery's early Afrofuturist roster, Stubbs makes no room for works that might dissolve the tight binary dynamic of the racial and historical codes that keep black and white music in their places, and so not only can his thesis not account for the works of Can or Byrne and Eno or other Outsider Afrofuturists, it doesn't account for the borrowings of Led Zeppelin, Bob Dylan or Blind Willie Johnson.

"Simultaneously SMUg ANd incredulous, it tells you", Eshun writes, "over and over, that Kraftwerk are Techno's precursors, its routes-rockers" (1999: 07 [104]). The Futurists that Eshun describes-Bambaataa with his white slitscan shades, Juan Atkins with his proliferation of machinic identities - are in fact creating Outsider identities that frustrate the implied value of the Other. They jettison altogether the value of a core identity assumed to be present behind a mask, a singularity and not a resingularisation, a note and not a polyphonic arrangement, a proper name and not a pseudonym. Eshun suggests an alternative to the pseudonym, which he calls "a heteronym, a many-name, one in a series of parallel names which distributes and disperses you into the public secrecy of open anonymity" (07[106]). For Eshun, Juan Atkins' multiple identities avoid the pitfalls of the pseudo-heteronymity of artists like David Bowie, Bob Dylan or Madonna, who made a career of rather dramatic shifts in persona and presence. Eshun calls these "serial heteronyms", and these are ultimately failed attempts to disperse the self through public anonymity $(07[106])$. Bowie shifts from Ziggy Stardust to Alladin Sane to the Thin 
White Duke. Dylan morphs from Guthrie-esque folk singer to electrified Beat rocker to mime to Born Again Christian. Madonna shifts from Material Girl to Vogue cover girl to Kabbalistic mystic. But Bowie and Dylan and Madonna are not about parallel identities, Eshun concludes. Beginning with the official retirement of Ziggy Stardust and the Spiders from Mars, each new Bowie album or so was marked by a new persona for much of his career. Each new persona, what Guattari calls “the 'extraction' and 'separation' of aesthetic subjectivities or partial objects" (1995: 19), stands in for a spark of renewed creativity; the whole project, it announces, has been recast. And yet we are also always made aware of the fact that it is David Bowie or, for that matter, Bob Dylan or Madonna, behind the masks. Look at how they've changed, we are told, or more acutely, look at how they've aged, caught up in the linear tug toward their own time of dying. Though Bowie, Dylan and Madonna play out the "essentially precarious, deterritorialising complexification" of heteronymity as a social phenomenon in the spotlight, they fall victim to the constant threat of "a reterritorialising subsidence" (1995: 19), invariably collapsing back to the aging identity of David Bowie, Bob Dylan or Madonna. ${ }^{11}$

In these cases, the assertion of the subject identity as an aging actor is a universalised, rather than resingularised, resolution of the production of alternate modalities of the self. And it is something that is jettisoned in Afrofuturist practice. Distinctions between serial and parallel modes of heteronymity are crucial. The heteronyms of the Afrofuturist are unique because they exist in parallel, and were once frequently anonymous at the core. ${ }^{12}$ In Eshun's words, "the Futurist producer is always greater than one, always multiplying into omni-duos, simultaneously diverging selves that never converge into knowledge of self. Instead of disciplining others through the despotic standard of keeping it real, staying true to the game, representing or staying black, Alien Music proliferates mindstates which never amount to mind. To unify the self is to amputate the self" (1999: 07[106-7]). Eshun's notion of parallel heteronymity rejects historical timelines and meta-narratives of linear influences and sequenced copies.

It is valuable to pull this rejection of cultural Fathers closer to Guattari's discovery of plural subjectivities in the domain of infant psychology. Guattari cites the research of the psychoanalytic theorist, Daniel Stern, whose The Interpersonal World of the Infant (1985) posits that infant development is not about Freudian stages, laid out sequentially; rather, infanthood arranges the "levels of subjectivation which maintain themselves in parallel throughout life" (Guattari 1995:6). Stern's understanding of "the inherently trans-subjective character of an infant's early experiences, which do not dissociate the feeling of self from the feeling of the other", coincides with Guattari's own clinical practice. Guattari approaches the treatment of psychosis and schizophrenia not in terms of retrieving a subjectivity that existed pre-crisis, but by encouraging instead the active production of new subjectivities and development of what Guattari describes as "universes [that] had been unknown" to the patient. The "universes" to which Guattari frequently refers function in collectives or complexes of subjectivation-Stern himself describes the "mother constellation"-that "offer people diverse possibilities for recomposing their existential corporeality, to get out 
of their repetitive impasses and, in a certain way, to resingularise themselves" (1995: 7).

I am interested in how the process of resingularisation explains the phenomena of the Outsider Afrofuturist, who shifts among channels for cross-technocultural transfer and identity mutation rather than operating by sequenced chains of influence, heredity and history. Resingularisation is not integration, racial or otherwise, and it is not about the retrieval of a lost, prior state of Selfhood or even Selflessness. But this just tells us what it is not. Guattari speaks more positively, describing "Grafts of transference [that] operate in this way, not issuing from ready-made dimensions of subjectivity crystallised into structural complexes, but from a creation which itself indicates a kind of aesthetic paradigm. One creates new modalities of subjectivity in the same way that an artist creates new forms from the palette" (1995: 7). Subjectivity is contingent. It is artistic, aesthetic and experimentally modal. As Žižek notes, the problem with multiculturalism consists of its attempts to unify the larger units of self, culture and race into an essential, single core that can be set aside, analyzed and evaluated from the "despotic standard" of the universal value, the Real that we are meant to keep representing. The privileging of the universality of the multiculturalist actually enacts a profound separation, however, and reinforces cultural amputation and isolation. The Outsider puts this to use.

\section{Serial Ethnoforgery in the Fourth World}

TyPICALLY, an ethnological recording will involve authentic instruments of a particular culture, playing traditional music of that culture, and ideally enlisting the performances of players from the given culture. ${ }^{13}$ The combination of these borrowed factors are intended to lend a pop album like Paul Simon's Graceland (1986) its air of authenticity despite its middle-of-the-road gloss of Afro-pop and South African styles. Perhaps the album's most pronounced stamp of authenticity was awarded when the United Nations Anti-Apartheid Committee deemed the album a worthy showcase of talented black South African musicians and singers despite the fact that Simon broke the boycott against South African apartheid to employ them. He did pay session musicians well, even giving a few of them co-writing and production credits, and the album's popularity increased the exposure of artists like Ladysmith Black Mambazo to a significant US market.

The authenticity of Simon's intent behind the project was touted in terms of global multiculturalism as it joined artists from South Africa to Ghana, though never at the same time. The album's multicultural credibility was also measured in terms of its worldwide success, selling over 16 million copies and placing consistently high in the music press and charts of many countries. But a more troubling yardstick of the project's authenticity is Simon's failure to credit the majority of his collaborators, including the American Chicano band, Los Lobos (see Bemis 2008). Reportedly, Simon did not come to sessions prepared with songs but asked his collaborators to jam out in the studio, a process apparently involving Simon and his recording engineer prompting session players through an abbreviated repertoire of traditional songs and their own compositions, played in the distinctive style of 
their culture (songs that sounded too mainstream and Western were canned from the getgo), until Simon could impose his own song structure onto their "authentic" jam. By mixing different segments of multiple songs, Simon and his mixing engineer cribbed together their own amalgamation, with Simon finally putting his lyrics over the top. At any rate, with the number of highly distinctive, ethnic music styles that Simon visits over the course of Graceland, it is hard not to hear the album as a document of ethno-musical tourism and cultural appropriation (see Zuckerman 2009).

This anecdote establishes some of the questions of intent, influence, collaboration, and honesty at the heart of the issue of ethnological forgery. But I want to consider more specifically the relationship of ethnoforgery to Afrofuturism, focusing on the concept of the "fourth world" articulated by Jon Hassell. Produced with Brian Eno, Hassell's Fourth World volumes were vehicles for what Hassell called the "future primitive", which he explored by combining contemporary technologies for sound treatment with ancient playing styles and instrumentation techniques, many adopted for his own trumpet. Hassell's unique horn style is most notably a variation of the vocal techniques of the Indian singer, Pandit Pran Nath, with whom Hassell studied Indian classical music. Surrounding the minimal, microtonal trumpet phrasing, Hassell and Eno built ambient environments out of delays, reverb, echo and other electronic effects of a mostly atmospheric nature. Tape loops, digital effects, human voice, congas, ghatan and synthesizers sit side by side on this record, and it is altogether weirder-like the almost uncomfortable loop that runs throughout the track, "Rising Thermal" - than what would come to be known as "world music" (and contemporary new age, for that matter). In Hassell's work, the ethnological sound functions as a vehicle for the imagination and speculation, and many of the inspirations came to Hassell indirectly. Dream Theory In Malaya was inspired after Hassell read a 1935 paper by ethnologist Kilton Stewart on the aboriginal Senoi tribe of the Malaysian highlands. The accounts of dreamlife as musical expression directly inspired Hassell's approach to this album, as did a BBC recording of the swamp-dwelling Semelai, who splash water in order to make rhythmic music. But it was ultimately an original synthesis of multiple world musics that Hassell was after.

Hassell's "fourth world" occupies a pivot in the history of ethnological forgery as a sophisticated meta-concept deployed specifically as a way to challenge received notions of national, racial and ethnic identities. Hassell's work suggests how a sense of world is assembled out of multiple technocultural identities. Hassell was prepped for these queries by studying under Karlheinz Stockhausen with both Holger Czukay and Irmin Schmidt of Can. Certainly, Hassell's Fourth World project extends Stockhausen's Hymnen (1966-7), the first major example of ethnological forgery in art music after World War II. Over the course of four "regions", Hymnen depicts the mixing, dissolution and transcendence of the nation state through the deconstruction of recorded national anthems, which combine and mutate into new polyphonies, both harmonious and discordant. Contrasted against often startling electronic outbursts and radio tunings, this powerful work provides a cosmic vantage on the earth, rendered here as radio waves that not only broadcast out from 
the planet but mix into new cultural amalgamations of music, sound and rhythm in the cosmos. The sonic deconstruction of the nation state leads to the final electronic new world anthem, represented as "Region Four", and concludes with Stockhausen's own exhalations. With this unique and significantly empty signature appended to the massive composition, Stockhausen inverts the field of hearing entirely, turning it inside out and making the whole thing somehow a cosmic identity trip, the sonic equivalent of Kubrick's Star Child.

Hassell inherits the post-national world of Stockhausen's Hymnen, drifting more toward the signature sounds of particular ethnological groups than anthemic recordings of the world's nations. Hassell doesn't strive for authentic representation but uses signature sounds as points of speculative departure and transfer of technique, style and dialect from one media base to another-from voice to trumpet, percussion to tape loops and processed guitar, water drum to keyboards. Hassell explains that his "aim was to make a music that was vertically integrated in such a way that at any cross-sectional moment you were not able to pick a single element out as being from a particular country or genre of music" (cited in Prendergast, 1991). Hassell's evocative description of the vertical stack of multiple cultural influences and sound signatures, operating polyphonically rather than sequentially, is symptomatic of the "alternative modernities" described by Dilip Parameshwar Gaonkar (2001). Gaonkar uses the term to distinguish the equally but differently modern cultures of the postcolonial period, an idea that Marcus Boon also uses to frame his analysis of montage in shamanism and contemporary ethnographic recording practices (2006). For Boon, the history of contemporary music demonstrates not only montage practices shared across the arts but is also the product of larger cultural montages:

One of the most interesting trends in contemporary music has been the fusion of these two kinds of montage - the "traditional" folk musical forms, with their various uses of appropriation and montage, and new technological means of creating montage effects, from turntablism, to laptop cut and paste and sampling, to the various techniques employed by the avant-gardes. This fusion of ethnic and avant-garde forms can be traced back as far back as the dadaists, who stole many of their techniques from traditional African arts, and then mixed them with print media; or the work of the minimalists, who mixed tape music with ethnomusicological theories and practices. Or Bob Dylan going electric, mixing Rimbaud with Appalachian folk song. Or Jamaican dub, itself a distorted echo of New Orleans music heard on far off radio stations across the Gulf of Mexico. Or hip hop, emerging out of the B-Boys' taste for African polyrhythms purloined from old vinyl reshaped and engineered on turntables and mixers for block parties in the Bronx (Boon 2006).

The alternative modernities of contemporary music appear to be products of ubiquitous ethnological copying and adaptation. But more significant for our understanding of Outsider Afrofuturism is the way in which the strategies of appropriation and montage push identity formation from national and racial into technological and cultural frames. This is an ethnological move, in fact, that recognizes and explores its own constructed, 
imaginary, or forged nature, which is what Boon, I think, means by "ethnopsychedelic". Hassell's "fourth world", then-the vertical stack of multiple, polyphonic cultural sound signatures-may in fact be symptomatic of the multiple cultural layerings, mixings and transfers encountered throughout contemporary music, but he engages this process at a more self-referential level.

The German band Can likewise demonstrates this kind of approach to multiple cultural influences on compositional and performance techniques, achieving synthesis in a "future primitive" aesthetic very different from Hassell's throughout their own "Ethnological Forgery Series". Can's Outsider Afrofuturist sound morphs out of a minimal, repetitive electric rock style cut from the mold of Velvet Underground-or the Monks, a tense tribal garage band of American ex-pat GIs who played edgy, itchy proto-punk songs like "Constipation" and "I Hate You" throughout Germany in the mid 1960s. Following the brief but high volume birth of Can as an Afrofuturist project proper-when they were fronted by African-American sculptor and drifter, Malcolm Mooney-Can's Outsider Afrofuturist project went further into ethno-pop forgery territory, first with another cultural transplant, Damo Suzuki, a former Cologne street-preacher from Japan, and second with Czukay's shortwave recordings. Can's ethnological forgeries depict an Outsider African voice drawn from Afro-Asian and North African sources unfamiliar to most Western ears accustomed to the black voices of American blues, soul, R\&B and funk. The result, at least as it plays out through most of Can's discography, is a globally scaled montage of ancient instruments and strange tonal vocabularies that result in new cultural hybrids and intentional sonic anomalies.

A forgery that announces it's a forgery, like Can's numbered "Ethnological Forgery Series", is not a very good forgery. But it does conduct a serious inquiry into the constructed nature of the ethnological and makes it the stuff of a significant, speculative exercise. I want to get at this general impulse as I close this section with reflections on Byrne and Eno's Afrofuturist work together. Byrne and Eno sustained their Afrofuturist explorations over the course of a number of weird dance albums-Bush Of Ghosts (1980) as well as the Talking Heads albums Fear Of Music (1979) and Remain In Light (1980). These are very self-conscious projects, beginning with the cover of Hugo Ball's faux primitive Dada enthnoforgery, "I Zimbra", on Fear Of Music (1979). Inspired by a binge on Jon Hassell's African pop and Afrobeat library, the original plans for Bush Of Ghosts included Hassell himself and called for a "series of recordings based on an imaginary culture", which they would then try to pass off as the real thing. "In our imaginings", Byrne recalls, "we'd release a record with detailed liner notes explaining the way music functioned in that culture and how it was produced-the kind of extensive notes common on those kinds of records" (Byrne 2006: 13-4).

This didn't quite happen as imagined when Byrne and Eno started adding "dance music" into the mix, ruining the project in Hassell's estimation. The dance element came in somewhat accidentally as Byrne and Eno's recording sessions were briefly influenced by an opportunity to record the score for a TV special with the singer and choreographer Toni Basil's dance troupe, The Electric Boogaloos. Ultimately, Byrne and Eno didn't so much 
create convincing ethnographic forgeries as much as artifacts from a Borgesian duplicate reality, a weird cultural variation of our own world broadcast through the spaces between radio stations. The convergence of dance music with the ethnological recordings eventually mutated and combined in the Byrne and Eno project as something that ultimately resides in the airwaves, as in Stockhausen's Hymnen, though this time in a deeply terrestrial-bound, bodily and haptic way rather than the cosmological perspectives and airy voids that bring Hymnen to a close. The ghosts in the bushes of Byrne and Eno are disco-funk, North African Arabic music, West African polyrhythms, as well as those of emerging hip-hop culture, especially the visible rhythms of breakdancers. The snapping, pop-locking bodies made for a powerful synchronization with the voices of American radio that Byrne and Eno were starting to record: preachers, evangelists, healers, finger-wavers and exorcists. There were buried oppositions there, ecstasies and hypocrisies that flittered through the spazzing body of evangelical revival.

\section{Ethnopsychedelic OUtsider SOUnd Systems}

BEGINNING with Bush Of Ghosts, Eno plays out a speculative future of global media that deploys the concept of "Africa" as a pre-emptive attack on the forces of digitization. $\mathrm{He}$ would rail against these forces and tendencies openly to Kevin Kelly in Wired magazine in 1995:

The problem with computers is that there is not enough Africa in them. This is why I can't use them for very long. Do you know what a nerd is? A nerd is a human being without enough Africa in him or her.... What's pissing me off is that it uses so little of my body. You're just sitting there, and it's quite boring. You've got this stupid little mouse that requires one hand, and your eyes. That's it. What about the rest of you? No African would stand for a computer like that. It's imprisoning (Eno, quoted in Kelly 1995).

Eno approaches African polyrhythms as a regimen of ancient haptic movement and affect poised against the docility of mainstream interfaces to digital culture. We have seen that this strategy seamlessly conflates with Byrne's persona of the herky-jerky white nerd possessed by deeply funky black grooves - the ecstatic fits and full body prayers-that Byrne would continue to explore with the Talking Heads, but it remains to be seen how deeply and to what significance this plays out in Eno's Afrofuturist work.

Eno's assessment and discussion of his own solo career repeatedly refer to Africa-the future of Africa in particular-and Eno has made notions of African sound, bodies and rhythm the crux of his critique of digital culture, especially in terms of human-computer interface design. ${ }^{14}$ Eno describes a desire for resingularisation in terms of "a vision that understands that we are creatures of intellect and of body, and that there isn't a strict separation between them" (quoted in Robinson 1981). He recalibrates the tensions between the ancient and the primitive, technology and ritual, intellect and body, as part of a polyphonic subjectivity that plays out through globally distributed and hypermediated 
forms. Eno hears these specifically as a "tremendously exciting . . collision of vernacular Western music with African music" (quoted in Kelly 1995). This media collision marks the moment of Afrofuturism's emergence as a unique strategy for engaging technologies across media not only to achieve ethico-aesthetic contact with the cultural flux-that is, "the collective assemblages of enunciation" that have the potential to yield "new Universes of reference" (Guattari 1995: 19) —but also as a strategy for new modalities of polyphonic subjectivity:

African music underlies practically everything I do-even ambient, since it arose directly out of wanting to see what happened if you 'unlocked' the sounds in a piece of music, gave them their freedom, and didn't tie them all to the same clock. That kind of free float - these peculiar mixtures of independence and interdependence, and the oscillation between them-is a characteristic of West African drumming patterns. I want to go into the future to see this sensibility I find in African culture, to see it freed from the catastrophic situation that Africa's in at the moment. I don't know how they're going to get freed from that, but I desperately want to see this next stage when African culture begins once again to strongly impact ours (Eno, quoted in Kelly 1995).

Eno associates Afrofuturism-literally by announcing his desire to go into the future and witness a liberated Africa - with strategies that give sounds their freedom.

For Eno, the blend of electronics and tribal instruments challenges "the old theory of the modern giving way to the post-modern", because it emphasizes the generation of new ideas by "the primitive, meaning the unchanged aspects of the old world" (quoted in Robertson 1981). Eno dismisses the value and usefulness of the "linear progression" of such historicisms, which collapse at the point of the "interface between primitive and futuristic". The collision of the future, embodied in Eno's discussion as "electronics", with the primitive, meaning "ethnological recordings and instrumentation", is at the heart of Eno's sense of the social, which functions in global culture under highly technological, specifically digital constraints.

Eno's work necessarily involves an emphasis on tape editing and audio mixing, digital sampling and manipulation, in order to create the strange amalgamation of global influences that he refers to as his "vision of a psychedelic Africa". Eno's vision shares with Marcus Boon's formulation a dual emphasis on ethnological exchange and montage as strategies for identity formation in an era of global media. Boon describes this kind of montage in terms of breaking the boundaries that multiculturalism, with its emphasis on the authenticity of the Other, puts in place. Boon suggests instead a position relevant to the Outsider aesthetics valued here:

More specifically, there is a range of performers and composers from around the world who have consciously worked to blur lines between traditional and contemporary methods of creating montage, making their montage in fact precisely by breaking the boundaries, cultural, disciplinary and otherwise, which appear to separate us and them (Boon 2006). 
Boon's approach to montage is rooted in terms of the rough and tumble practice of ethnological field recordings, typically recordings of shamanist events, trances and other altered states of consciousness. Boon's major points of reference are important, not academically sanctioned sources of ethnological field recordings but the work of Outsider ethnomusicologists like Henry Flynt and Harry Smith, as well as the more contemporary Sublime Frequencies label. These particular artists "share an interest in breaking through consensus reality, producing a direct transformation of consciousness, either in the listener or performer" (Boon 2006).

The consciousness-changing "ethnopsychedelic music" described by Boon and recorded by Eno enacts Žižek's rejection of multiculturalism in compositional terms by opposing the totalizing and universalist agenda of both the distanced, impartial recordings encountered in the Smithsonian archives as much as the "smooth fusions" of so-called new age world music. Instead, the ethnopsychedelic is "a music of strange jumps, juxtapositions and alliances that are not situated easily on either side of the modern/traditional divide" (Boon 2006). The technological and cultural dimension of this collision, "the cacophony of modernity", involves complex sound worlds that support resingularisation and resist reterritorialisation into racial and nationalistic models. Boon's opposition between "ethnopsychedelic music" and "smooth fusion world music" suggests a large-scale version of Eshun's heteronymic identity. The so-called Globe, or even more sweetened up, the Global Village, of multiculturalism collapses through what the comic books call an infinite crisis on multiple earths.

Similar distinctions between the ethnopsychedelic and smooth fusion approaches to world music are found in Eno's statements about Africa, music and digitization. When interviewed by Sandy Robertson for Sounds magazine in 1981, Eno was asked to explain why he had been making so many comments about Africa and its increasing importance "not just musically but to all aspects of life" (Robertson 1981). Eno launches into an anecdote about tuning in, just that morning, to a New York radio program about the African influence on contemporary music and being amazed at the number of "records by people using electronics and basically tribal instruments, and doing it very successfully on a lot of occasions". Unfortunately, Eno doesn't mention any particular artists or cuts that he heard that morning, ${ }^{15}$ but his point is that he wasn't the only one to experience this "African psychedelic vision". To the contrary, "there were clearly a lot of other people tuning in to it at the same time", and Eno hoped that this pointed to a general shift away from the excessive technology-fetishism of much synthesizer music as well as both popular and academic strains of electronic music toward more radically hybrid forms (Eno, quoted in Robertson 1981). What Eno's people were tuning into was a kind of rhythmic technocultural subjectivity, new subject formations patterned by the velocities of those living outside, the heterogeneic, the polyphonic and the partial.

Where Hassell drew on ethnomusicology and anthropology for sources of speculation, Byrne and Eno turned the techniques of the ethnomusicologist back onto American media, particularly the charismatic end of evangelical radio and conservative talk shows. In his 
notes to the 2006 re-issue of Bush Of Ghosts, Paul Morley suggests that the extrapolation of different pop histories and a "new kind of hybrid" America informed Eno and Byrne's work together:

They wondered what it would be like if pop music had not been so American, or so European, or so disconnected from the rhythms and textures that first inspired the music that first inspired pop. They imagined a future, or even a present, where pop music might sound like this - might in fact sound like it was music that was the pop music of an imaginary society. Their imagining of an imaginary society that was familiar with music like this has helped actually create that world-it's one of those things that makes certain records have lasting stature, that, by taking forward the ideas and thoughts of others, and shaping them into a new identity and image, they actually do make a difference to the sound, and often the appearance, of the world (Morely 2005).

Upon its release, Bush Of Ghosts was met by more confusion and derision than Morley's reflections on the re-issue, twenty-five years down the road, would suggest. The album was rejected as overly intellectual, and the use of sampled voices in place of the artists' own frustrated many listeners. In his review of the album for Rolling Stone in August 1981, Jon Pareles accuses Byrne and Eno of "cultural imperialism". He recognizes that as the treatment of a newly emerging global culture of hypermedia, Bush Of Ghosts is deeply McLuhanesque in its strategy of sampling "the global media blitz": "edit, add polyethnic rhythm tracks, name the results after a novel by Nigerian author Amos Tutuolo and recycle them into the blitz" (Pareles 1981). Pareles is suspicious of such cross-cultural, appropriative "found art". But the concerns that he raises about the ways in which the experience, voice and soundscape of the Other is appropriated without credit being given, much less financial remuneration, and with no respect for original context, seem more relevant to Paul Simon's Graceland than Byrne and Eno's Bush Of Ghosts. Paul Simon subsumed the creative labors of living musicians into the idealized past of the American father, Elvis and his home, Graceland; more practically, all sounds become unified by Simon's lyrics and voice. And this marks the biggest difference between Simon's Graceland and Byrne and Eno's Bush Of Ghosts.

On Bush Of Ghosts, the use of vocal samples undermines the presence of the lead singer. Voices are looped and sequenced and otherwise reconstructed from snippets of a preacher's sermon, an exorcism, or a talk radio rant until they resemble the lyrical delivery of a pop song. The sample is the auditory equivalent for the possession of the body by the extreme, exaggerated and even fitful rhythms of polyphonic subjectivity that Byrne and Eno unleash. On stage with the Talking Heads, ${ }^{16}$ Byrne's body becomes the vehicle of what Guattari calls "poetic-existential catalysis" (1995: 19). The construction of imaginary ethnographies through a cross-pollinating mixture of multiple cultural and ethnological sources ultimately catalyzes Byrne's body as a vehicle for global polyphonic subjectivity. As we will see, this bodily response to the intense technological and cultural montage is at the heart of Eno and Byrne's project and would continue to shape Eno's assessment of the need for Africa in digitized environments. 
The multiculturalist tendency that Žižek describes and Pareles maintains requires the specificity of the Other in order to allow the multiculturalist to measure and maintain the universal values of multiculturalism - the Other, under scrutiny, may be appreciated or depreciated in this process. In either case, the measuring distance, which maintains the superiority of the multiculturalist vantage, is really an empty point. The universal values of multiculturalism fail to invert (unlike Stockhausen's breathy black hole of artificial closure, first breath or last breath, we'll never know) and never become part of a self-referential and critically reflective process that turns back on the inquiring subject-which is precisely what Byrne and Eno sought to do when they scanned the fringes of American radio as though strangers in their own land, looking for new voices and imagining the bodies that went with them.

A bit punkish in attitude, Byrne and Eno did not approach any of their subjects with the carefully studied and respectful poise of the liberal multiculturalist ethnographer that Pareles advocates. They hadn't even read Amos Tutuolo's book when they nicked his title, and since there were few channels for "world music" at the time, much of the pair's impressions of Africa came from reading the works of cultural anthropologists and ethnomusicologists and then imagining how this music might sound. In fact, Byrne and Eno were drawn to Tutuolo's title along sympathetic channels just as the Talking Heads were drawn to imitate Joy Division's atmospheric sound in "The Overload", a sound they imagined based entirely on their reading reviews of, rather than actually listening to, anything by Joy Division (Reynolds 2005: 139). This strategy of projecting an imaginary double-or a whole land of imagined doubles-whose sound the band then attempts to duplicate is precisely what we encounter in Bush Of Ghosts. Byrne and Eno seek a kind of possession by unknown voices and rhythms, not just of "primitive Africa" but of white evangelical outsiders who imagine themselves at the center of the spiritual universe, of the demonically possessed and their exorcists-all manner of Outsiders, the Outsiders on the inside, even Outsiders to the Outsiders.

\section{NOTES}

1 Specifically, I am listening here to Hassell's two Fourth World albums, Possible Worlds (1980) and Dream Theory In Malaya (1981), Can's numbered "Ethnological Forgery Series" and Soon Over Babaluma (1974), Byrne and Eno's My Life In The Bush of Ghosts (1980), and Talking Heads' Fear Of Music (1979) and Remain In Light (1980).

2 See Istvan Csicsery-Ronay, Jr., The Seven Beauties of Science Fiction (2008: 11-12).

3 Dery suggests that as a literary, critical, and publishing market subaltern-Dery cites both Gibson, who calls science fiction a "golden ghetto" (cited in Dery 1994: 180) and Norman Spinrad, who once suggested that a science fiction writer adopted by the literati is merely their "token nigger" (1990: 9) - science fiction would seem to be a perfect fit for the AfricanAmerican artist.

4 The disenfranchisement of the African-American during the space age is well-documented 
and frequently the stuff of major Afrofuturist cuts, like Gil-Scott Heron's rant "Whitey on the Moon" (1970), which plays out a ghetto drama shaped by the apotheosis of the media, technology, the future, and white American culture that was the Apollo moon landings, the first globally televised event.

5 John Sayles's The Brother from Another Planet (1984) and Lizzie Borden's Born in Flames (1983); Milestone Media's Hardware and Icon (1993); visual artists Basquiat and Rammellzee.

6 Dery zooms in on the science fiction elements of Jimi Hendrix, Miles Davis, Herbie Hancock's Headhunters (and solo work), Bernie Worrell, and George Clinton. Dery also sketches several Afrofuturist subgenres and a few representatives, including electro (Planet Patrol, Warp 9), Detroit techno (Cybotron, Juan Atkins, Kevin Saunderson, Derrick May), dub (Lee "Scratch" Perry, the sole international artist on the list), and New York hip-hop (Afrika Bambaataa).

7 It is still surprising how many major artists are actually missing from Dery's early roster. Sun Ra is name-checked but the later cosmic works of both John and Alice Coltrane are overlooked. Missing too are the dub stylings of Scientist, Detroit techno legend Jeff Mills's X-102 Discovers The Rings Of Saturn (tresor.004, 1992), the earliest recordings of Detroit electro outfit Drexciya, "Deep Sea Dweller" (1992) and "Drexciya 2: Bubble Metropolis" (1993), and the original UK dub album, Creation Rebel's Starship Africa (recorded 1978, released 1980), with Adrian Sherwood producing. It is also amazing how many Afrofuturist works, American or otherwise, were on the cusp of emerging on the scene shortly after Dery's Flame Wars was published, including A Guy Called Gerald's Black Secret Technology (1995), Larry Heard's Alien (1996), and the increasingly complex aqua-afro cosmology of Drexciya that unfolded on albums like The Quest (1997), Neptune's Lair (tresor.129, 1999) and the Shifted Phases sideproject, The Cosmic Memoirs Of Rosinthrope (tresor.196, 2002). Also to note here in hip-hop would be OutKast's ATliens (1996) and the Wu-Tang Clan's 36 Chambers (1993).

8 With their deft mix of break beats, synthesizers, robotic voices, hair-metal guitar and sequenced bass lines, Cybotron's early singles, "Cosmic Cars" (1982) and "Clear" (1983) are frequently cited as the genre-defining progenitors of Detroit techno and electro.

9 Just listen to Billie Holiday's "Strange Fruit", especially and unexpectedly terrifyingly paired with "Fine and Mellow", released in 1939; classic 1970s socially-conscious soul like Stevie Wonder's Songs In The Key OfLife (1976) and Marvin Gaye's What's Going On? (1971) —or almost anything recorded by Gil-Scott Heron.

10 Seen on the Led Zeppelin DVD (2003).

11 Dylan may have successfully voided this root identity entirely, evacuating the subject behind the name. See Seeburger (2006).

12 Though this has admittedly changed in the current age of techno superstars and big-name producers.

13 For example, as carried out in the work of John Lomax, the musicologist and folklorist who pioneered the field of recording ethnological subcultures, finally curating the Archive of American Folk Song. Some of the major recording labels releasing more traditional ethnological recordings include Rough Guide and the World Music Network, Smithsonian Folkways, Nonesuch Explorer, Unesco and Chant Du Monde.

14 See the list of interviews and articles reprinted at Hyperreal's enoweb: <http://music. hyperreal.org/artists/brian_eno/interviews/intindex.html >. 
15 Candidates might include XTC's “It's Nearly Africa”, Peter Gabriel's “Across The River”, and The English Beat's "Mirror In The Bathroom", all cuts included on The Best Of Music And Rhythm LP that benefitted Gabriel's WOMAD (A World of Music Arts and Dance) festival. 16 See Jonathan Demme's concert film Stop Making Sense (1984).

\section{REFERENCES}

Ballard, J. G. 1985. "Introduction to the French Edition" (1974). Crash. New York: Vintage. Bemis, Alec Hanley. 2008. "Los Lobos on Paul Simon: 'Do you mean zydeco when you say zy decko?’” LA Weekly. <http://blogs.laweekly.com/westcoastsound/teenage-kicks/los-lobos-onpaul-simon-do-you-1> (accessed 19th October 2009).

Boon, Marcus. 2006. “Sublime Frequencies' Ethnopsychedelic Montages”. Electronic Book Review. <http://www.electronicbookreview.com/thread/musicsoundnoise/ethnopsyche>. (accessed 4th October 2009).

Butler, Octavia. 1987. Dawn. New York: Warner Books.

———. 1988. Adulthood Rites. New York: Warner Books.

-_- 1989. Imago. New York: Warner Books.

Byrne, David with Brian Eno. 2006. “The Making of My Life in the Bush of Ghosts”. Liner notes to My Life In The Bush Of Ghosts. Nonesuch / EMI Records (US): 79894-1.

Csicsery-Ronay, Jr., Istvan. 2008. The Seven Beauties of Science Fiction. Middletown, CT: Wesleyan University Press.

Delany, Samuel. 1975. Dhalgren. New York: Bantam Books.

Dery, Mark. 1994. "Black to the Future: Interviews with Samuel R. Delany, Greg Tate, and Tricia Rose". In Flame Wars: The Discourse of Cyberculture. ed. Mark Dery, 179-222. Durham: Duke University Press.

Ellison, Ralph. 1947. Invisible Man. New York: Vintage International.

Eshun, Kodwo. 1999. More Brilliant Than the Sun: Adventures in Sonic Fiction. London: Quartet.

Fuller, Matthew. 2005. Media Ecologies: Materialist Energies in Art and Technoculture. Cambridge: MIT Press.

Gaonkar, Dilip, ed. 2001. Alternative Modernities. Durham: Duke University Press.

Guattari, Félix. 1995. Chaosmosis: An Ethico-Aesthetic Paradigm. Trans. Paul Bains and Julian Pefanis. Bloomington \& Indianapolis: Indiana University Press.

Kelly, Kevin. 1995. "Gossip Is Philosophy”. Wired 3.05. < http://www.wired.com/wired/ archive/3.05/eno.html > (accessed 4th October 2009).

Lovecraft, H.P. 1982. "The Outsider". The Best of H. P. Lovecraft: Bloodcurdling Tales of Horror and the Macabre, 27-32. New York: Ballantine Books.

Morley, Paul. 2005. "What if Brian Eno and David Byrne Made an Album that took its Title from a 1954 Book by the Nigerian Writer Amos Tutuola?" My Life in the Bush of Ghosts Website. <http://bushofghosts.wmg.com/essay_1.php> (accessed 4th October 2009).

Pareles, Jon. 1981. “Does This Global Village Have Two-Way Traffic?” Rolling Stone 340. < http://bushofghosts.wmg.com/archive_press.php?id=3> (accessed 4th October 2009). 
Prendergast, Mark. 1989. "Brian Eno: 'A fervent nostalgia for the future'-Thoughts, Words, Music and Art, Part One”. Sound On Sound 4(3). <http://music.hyperreal.org/artists/ brian eno/interviews/sos 1.html $>$ (accessed 4th October 2009).

- - - "Interview with Jon Hassell". 1991. Sound on Sound (July). < http://www.jonhassell. com/soundon.html> (accessed 4th October 2009).

Rasmussen, Terje. 2003. "On Distributed Society: The Internet as a Guide to a Sociological Understanding of Communication”. Digital Media Revisted. eds. Gunnar Liestøl, Andrew Morrison and Terje Rasmussen, 443-67. Cambridge: MIT Press.

Reynolds, Simon. 2005. Rip It Up and Start Again: Postpunk 1978-1984. London: Faber and Faber.

Robertson, Sandy. 1981. "The Life of Brian in the Bush of Ghosts". Sounds (March $7^{\text {th }}$ ). $<\underline{\text { http://music. }}$ hyperreal.org/artists/brian eno/interviews/sound81a.html> (accessed 4th October 2009).

Seeburger, Francis F. 2006. “9/11 Never Happened, President Bush Wouldn't Let It: Bob Dylan Replies to Henri Bergson”. Electronic Book Review. <http://www.electronicbookreview.com/ thread/musicsoundnoise/eventual > (accessed 4th October 2009).

Spinrad, Norman. 1990. Science Fiction in the Real World. Carbondale: Southern Illinois University Press.

Stern, Daniel. 1985. Interpersonal World Of The Infant: A View From Psychoanalysis And Developmental Psychology. New York: Basic Books.

Stubbs, David. 2009. Fear of Music: Why People Get Rothko but Don't Get Stockhausen. London: Zero Books.

Taylor, Timothy. 2001. Strange Sounds: Music, Technology and Culture. New York: Routledge. Veal, Michael. 2007. Dub: Soundscapes and Shattered Songs in Jamaican Reggae. Middletown: Wesleyan University Press.

Žižek, Slavoj. 1997. "Multiculturalism, or the Cultural Logic of Multinational Capitalism”. New Left Review 225: 28-51.

Zuckerman, Ethan. 2009. "From Protest to Collaboration: Paul Simon's "Graceland" and Lessons for Xenophiles". My Heart's in Accra. < http://www.ethanzuckerman.com/blog/2009/04/02/ from-protest-to-collaboration-paul-simons-graceland-and-lessons-for-xenophiles $/>$ (accessed 4th October 2009).

\section{DISCOGRAPHY}

1970's Algerian Proto-Rai Underground. 2009. Sublime Frequencies (US): SF045CD. < http:// www.discogs.com/Various-1970s-Algerian-Proto-Rai-Underground/release/1842448>.

Afrika Bambaataa And The Soul Sonic Force. Planet Rock. 1982. Tommy Boy Music (US): TB 823. < http://www.discogs.com/Afrika-Bambaataa-Soulsonic-Force-Planet-Rock/ master/19152>.

Beat Pharmacy. 2005. Earthly Delights. Deep Space Media (US): WM50151-2. <http://www.discogs.com/Beat-Pharmacy-Earthly-Delights/master/145002>.

———. 2007. Steadfast. Deep Space Media (US): DS50173-2. <http://www.discogs.com/Beat-Pharmacy-Steadfast/release/1011369>. 
The Best Of Music And Rhythm. 1982. PVC Records (UK): PVC 6902. <http://www.discogs.com/Various-The-Best-Of-Music-And-Rhythm/release/2868336>.

Burial. 2006. Burial. Hyberdub (UK): HDBCD001. <http://www.discogs.com/Burial-Burial/master/11767>.

- - 2 2007. Untrue. Hyberdub (UK): HDBCD002. <http://www.discogs.com/Burial-Untrue/master/11772>.

Byrne, David and Brian Eno. 1980/2006. My Life In The Bush Of Ghosts. Nonesuch (US): 798941. < http://www.discogs.com/Brian-Eno--David-Byrne-My-Life-In-The-Bush-Of-Ghosts/ master/6392>.

Can. 1974. Limited Edition. United Artists (UK): USP 103. < http://www.discogs.com/Can-Limited-Edition/master/17054>.

——_. 1974. Soon Over Babaluma. United Artists (UK): UAG 29673. <http://www.discogs.com/Can-Soon-Over-Babaluma/master/11485>.

Creation Rebel. 1981. Starship Africa. On-U Sound (UK): ON-U LP 08. <http://www.discogs.com/Creation-Rebel-Starship-Africa/master/19386>.

Cybotron. 1990. Clear. Fantasy (US): FCD-4537-2. <http://www.discogs.com/Cybotron-Clear/master/134>.

dBridge. 2008. The Gemini Principle. Exit Records (UK): EXITCD002. <http://www.discogs.com/dBridge-The-Gemini-Principle/master/60158>.

Dub Syndicate. 2001. Acres Of Space. Lion and Roots (Germany): Lion \& Roots 05. <http://www.discogs.com/Dub-Syndicate-Acres-Of-Space/master/19207>.

Gaye, Marvin. 1971. What's Going On. Tamla (US): TS 310. <http://www.discogs.com/Marvin-Gaye-Whats-Going-On/master/66631>.

Hassell, Jon. 1981. Dream Theory In Malaya / Fourth World Volume Two. Editions EG (UK): EGED 13. <http://www.discogs.com/ Jon-Hassell-Dream-Theory-In-Malaya-Fourth-World-Volume-Two/master/33904 >.

Hassell, Jon and Brian Eno. 1980. Fourth World Vol. 1: Possible Musics. Editions EG (UK): EGED 7. <http://www.discogs.com/ Jon-Hassell-Brian-Eno-Fourth-World-Vol-1-Possible-Musics/master/12068>.

Heavyweight Dub Champion. 2002. Survival Guide For The End Of Time. Champion Nation Recordings (US): CN70002. <http://www.discogs.com/ Heavyweight-Dub-Champion-Survival-Guide-For-The-End-Of-Time/release/871898>.

Heron, Gil-Scott. 1971. Small Talk at 125 ${ }^{\text {th }}$ And Lenox. Flying Dutchman (US): FD 10131. <http://www.discogs.com/Gil-Scott-Heron-Small-Talk-At-125th-And-Lenox/master/7675>.

Holiday, Billie. "Strange Fruit/Fine And Mellow". 1939. Commodore (US): 526. <http://www.discogs.com/Billie-Holiday-And-Her-Orchestra-Strange-Fruit-Fine-AndMellow/release/1634405>.

Hydroponic Sound System. 2000. Routine Insanity. Blackheart (US): B00004YWVR. <http://www.alt-take.com/discography.asp $>$.

Kode9 and The Spaceape. 2006. Memories Of The Future. Hyperdub (UK): HYPCD001. <http://www.discogs.com/Kode9-Spaceape-The-Memories-Of-The-Future/master/103371>.

Noiseshaper. 2006. Real To Reel. Echo Beach (Germany): EB059. < http://www.discogs.com/ Noiseshaper-Real-To-Reel/release/813431>. 
Perry, Lee "Scratch" and Dub Syndicate. 1987. Time Boom X De Devil Dead. On-U Sound (UK): ON-U LP 43C. <http://www.discogs.com/ Lee-Scratch-Perry-Dub-Syndicate-Time-Boom-X-De-Devil-Dead/master/19344>.

Radio Palestine: Sounds Of The Eastern Mediterranean. 2004. Sublime Frequencies (US): SF008. $<$ http://www.discogs.com/Various-Radio-Palestine-Sounds-Of-The-Eastern-Mediterranean/ release $/ 1115970>$.

Radio Pyongyang: Commie Funk And Agit Pop From The Hermit Kingdom.

2005. Sublime Frequencies (US): SF023. < http://www.discogs.com/Various-

Radio-Pyongyang-Commie-Funk-And-Agit-Pop-From-The-Hermit-Kingdom/ release $/ 820378>$.

Sandoz. 1993. Digital Lifeforms. Touch (UK): TO:21.

<http://www.discogs.com/Sandoz-Digital-Lifeforms/release/47103 >.

- - 1996. Dark Continent. Touch (UK): Tone 4CD.

< http://www.discogs.com/Sandoz-Dark-Continent/release/145312>.

- - . 2001. Afrocentris. Intone (UK): INTONECD001. < http://www.discogs.com/Sandoz-Afrocentris/release/108442>.

-C- 2006. Live In The Earth: Sandoz In Dub (Chapter 2). Soul Jazz Records (UK): SJR CD 130. < http://www.discogs.com/Sandoz-Live-In-The-Earth-Sandoz-In-Dub-Chapter-2/ master/70369>

Simon, Paul. 1986. Graceland. Warner Bros. Records (US): 9 25447-2. $<$ http://www.discogs.com/Paul-Simon-Graceland/master/55658 >.

Stockhausen, Karlheinz. 1995 (1967-8). Hymnen. Stockhausen-Verlag (Germany): Stockhausen 10. < http://www.discogs.com/Stockhausen-Hymnen/release/730162>.

Talking Heads. 1979. Fear Of Music. Sire Records (US): SRK 6076. <http://www.discogs.com/Talking-Heads-Fear-Of-Music/master/39260>.

- - 1980. Remain In Light. Sire Records (US): SRK 6095. <http://www.discogs.com/Talking-Heads-Remain-In-Light/master/25688>.

Wonder, Stevie. 1976. Songs In The Key Of Life. Tamla (US): T13-340C2. <http://www.discogs.com/Stevie-Wonder-Songs-In-The-Key-Of-Life/master/87440 >.

FILMOGRAPHY

Borden, Lizzie. 1983. Born In Flames. <http://www.imdb.com/title/tt0085267>.

Carruthers, Dick. 2003. Led Zeppelin DVD. < http://www.imdb.com/title/tt0366707>.

Coney, John. 1974. Space Is the Place. < http://www.imdb.com/title/tt0072195>.

Demme, Jonathan. 1984. Stop Making Sense. <http://www.imdb.com/title/tt0088178>

Sayles, John. 1984. The Brother From Another Planet. <http://www.imdb.com/title/tt0087004 >. 